\title{
Obesity in primary care: evidence for advising weight constancy rather than weight loss in unsuccessful dieters
}

\author{
Rachel Pryke and Andrea Docherty
}

\begin{abstract}
In view of the limited success rates of all weight-loss strategies to date, this article hypothesises that in situations where previous dieting attempts have failed, better outcomes and health improvements will arise from advocating weight-stability goals. This means the promotion of weight maintenance (to ensure any reduction in weight is maintained) and weight constancy (where steps are taken to maintain existing weight without attempting weight loss), rather than advocating existing 5-10\% weight-loss targets for these patients. The majority of approaches to obesity focus on weight reduction despite poor evidence of effectiveness. Primary care remains reluctant to engage in ineffective approaches, yet is well placed to give advice, and would undoubtedly adopt effective obesity-management approaches if they were developed. Despite guidance for overweight or obese people to aim for a $5-10 \%$ weight reduction, current trends demonstrate escalation of average weights and obesity. A literature review found little information about evaluation of weight-stability approaches (either weight maintenance or weight constancy), despite theoretical support for them. Yet taking steps to protect weight reduction where it is achieved, and to promote weight constancy (without weight loss) where further dieting is predicted to fail, would have a beneficial effect on preventing further growth of obesity-related morbidity in the population. Some evidence exists to support simple behavioural approaches to improve weight stability, but these measures do not feature in current advice and hence are not widely advocated.

Keywords

obesity; unsuccessful diet; weight constancy; weight gain; weight stability.
\end{abstract}

\section{OBESITY IN CONTEXT}

Within the last 25 years the proportion of adults with obesity in the UK has grown fourfold. ${ }^{1}$ This is apparent in the rising trend of obesity in recent years: between 1993 and 2002 the percentage of men with obesity has increased from $13.4 \%$ to $22.9 \%$ and in women it has increased from $17 \%$ to $25.4 \%$. $^{2}$ The UK compares poorly with the rest of Europe where average increases in obesity prevalence range between $10 \%$ and $40 \%$ in the last 10 years, in contrast to England where the rate has more than doubled. ${ }^{3}$ If nothing is done to halt the rise in adult obesity, it is estimated that around 12 million adults and 1 million children will be obese by 2010 . In relation to adults, this will mean that between 2003 and 2010 a further 3.5 million adults previously of healthy weight or with a body mass index (BMI) of less than $30 \mathrm{~kg} / \mathrm{m}^{2}$ will shift into either the overweight or obese range. ${ }^{4}$

Without specific care to maintain existing weight, the majority of the population risks gradual weight gain averaging around $0.8 \mathrm{~kg}$ per year. ${ }^{5}$

The sequelae of obesity are profound and contribute to other conditions that GPs are actively treating, such as hypertension, cardio- and cerebrovascular disease, and diabetes. ${ }^{6}$ The large INTERHEART multinational study listed obesity as one of the nine major modifiable risk factors for myocardial infarction. ${ }^{7}$ Percentage body fat is a risk

R Pryke, MRCGP, GP, Winyates Health Centre, Redditch, Worcestershire, Member of Worcestershire Obesity Reduction and Prevention Strategy Group, Member of Adolescent Task Group of the Royal College of General Practitioners; A Docherty, BA, MSc, PhD, MPH, specialist trainee in public health, Public Health Team, Worcestershire PCT, Worcester.

Address for correspondence

R Pryke, Winyates Health Centre, Redditch, Worcestershire, B98 ONR. E-mail: rachelgpryke@tiscali.co.uk

Submitted: 21 August 2007; Editor's response: 16 October 2007; final acceptance: 27 November 2007.

(c)British Journal of General Practice 2008; 58: 112-117.

DOI: 10.3399/bjgp08X277023 
factor for coronary events, ischaemic stroke, and cardiovascular disease mortality. ${ }^{8}$ Additionally, there are major economic costs from direct treatment and indirect costs, such as sickness absence, totalling $£ 3.5$ billion in England in $2002 .{ }^{9}$ Quality-adjusted life expectancy is estimated to be reduced by 3 years in males and 6 years in females in the presence of obesity. ${ }^{10}$ If effective treatments were available, there is little doubt that the GP workforce would enthusiastically get involved.

\section{FOCUS OF THIS PAPER}

The evidence base for obesity interventions remains inadequate, despite its high profile in political and research arenas. ${ }^{11}$ All approaches studied show limited effectiveness, with the possible exception of surgery. ${ }^{3}$ Weight loss of 3-5 kg maintained for up to a year is considered a reasonable expectation from any dieting approach, whereas surgery has achieved sustained weight reduction of $20 \mathrm{~kg}$ or more according to various studies. ${ }^{12}$ If an individual's 5-10\% weight-loss goal ceases, evidence shows that more weight is regained than was initially lost. ${ }^{6}$

In view of the disheartening finding in April 2007, from a major review of 31 long-term weightreduction studies, that dieting is a consistent predictor of future weight gain, ${ }^{6}$ this article explores the hypothesis that encouraging prevention of further weight gain, rather than aiming for weight loss, would at least help to prevent current levels of obesity from escalating further, and would thus generate health gains on a population level. This potentially achievable concept has yet to be widely discussed or adopted in any practical sense.

\section{PRIMARY CARE HAS YET TO ENGAGE FULLY WITH OBESITY MANAGEMENT}

The arrival of obesity-related points in the Quality and Outcome Framework has triggered concern from GPs about the expectations of primary care in future obesity management, including fear of a fundamentally societal problem being foisted on general practice. Little common ground has been found between the two extreme viewpoints: that obesity is the illness versus the view that, while obesity causes illness, it stems from societal or personal issues and hence is not a doctor's sole responsibility to treat it. Most doctors recognise arguments supporting both approaches, and the reasons for inaction are not a lack of appreciation of its profound health sequelae, but rather the lack of evidence that levels of obesity can be influenced by the personal interests and efforts of doctors.

The terms used in this paper are defined as follows:

\section{How this fits in}

Many studies show the varied and substantial health benefits of moderate $(5 \%)$ weight loss, but there is little guidance about management options for people who fail to maintain weight loss, fail to lose any weight, or who achieve less than the primary-care target of $5 \%$ weight reduction. As average weight is increasing each year, measures to promote weight constancy may have a significant benefit at a public-health level. Simple behavioural measures may help to promote weight constancy, but do not yet feature in routine weight management advice in primary care. This study evaluates some of the evidence that supports development of weight constancy approaches.

- 'weight maintenance' is used to describe maintained weight following weight loss;

- 'weight constancy' is used to describe avoiding further weight increase even where no weight reduction has been attempted; and

- 'weight stability' is used when both concepts are referred to.

Current obesity-prevention work is targeted at schools and activity initiatives, with very little development of primary care prevention approaches to date.

\section{EXISTING WEIGHT-LOSS TARGETS RISK GENERATING MIXED MESSAGES OF FAILURE}

The National Institute for Health and Clinical Excellence's (NICE's) obesity guidance, released in December 2006, focuses on weight reduction and advises a target of $5-10 \%$ weight-loss. ${ }^{13}$ While it mentions weight maintenance in various contexts, it does not elaborate on any specific approaches, and weight constancy is not discussed at all. For people who are not ready to engage in change, it recommends explaining the benefits of weight loss (an approach they are often not ready to adopt), whereas the opportunity for recommending the relevant and potentially achievable target of weight constancy is missed. There is no patient literature available on the merits of weight constancy, and unfortunately an ethos of failure pervades those dieting attempts that fizzle out, including among staff overseeing weight management in primary care.

As these NICE guidelines use the existing evidence base for obesity management, they do not address many questions on best practice: these are yet to be established. For example, they do not clarify how to help people who are successful in losing small amounts of weight with obesity medication, but who fail to achieve the recommended $5 \%$ reduction - have they failed or 
have they succeeded? Certainly, they are more likely to fail if their medication is withdrawn. ${ }^{14}$ Active ongoing support for either weight constancy or weight maintenance raises resource implications, but resources are currently directed at weight-loss services instead.

Thus, a patient who initially loses $3 \mathrm{~kg}$ in a weight-management clinic but then plateaus and regains a little weight, will probably have their obesity medication withdrawn, confirming their sense of failure and draining motivation for further self-help. This scenario is common when goals are set at a minimum of $5 \%$ weight reduction. And a patient with obesity who demonstrates negligible weight loss is seen as untreatable rather than being encouraged to aim for the possibly attainable goal of simply staying the same weight, even though we can safely predict that, without any action, further weight gain is probable.

A change to this approach is essential in view of the poor research statistics on longer-term sustained weight loss. Most (although not all) individuals who successfully lose $10 \%$ of initial body weight will regain around two-thirds of it within only 1 year, and the remainder over the following 5 years. ${ }^{15}$ In the light of the adage 'First do no harm', the worrying phenomenon of rapid weight regain has multiple negative effects including the facilitation of yo-yo dieting and negative consequences for both the metabolic system and the motivational self-efficacy of the individual. ${ }^{1}$

Unfortunately, weight management in general practice, with or without obesity medication, is no more effective than any other dieting approach, such as commercial slimming clubs and self-help approaches. ${ }^{14,16}$ Obesity is a chronic condition, and only surgery has been shown to be more effective, but it is limited by lack of resources as well as lack of facility to treat the large numbers of people who would fit eligibility criteria.

The widely advocated primary care obesitymanagement method, the Counterweight Project, demonstrated an average $2.4 \mathrm{~kg}$ weight reduction, rising to $3.3 \mathrm{~kg}$ in high attenders, but there was a discontinuation rate of over $50 \% .{ }^{17}$ Considering the significant training and dedicated time required from GPs or practice nurses, these results do not demonstrate sufficient improvement over traditional advice to justify this level of investment. Uptake of the Counterweight Project has been low, particularly as lack of funding has been an issue. ${ }^{13}$

There is no dispute that losing 3-5 kg generates measurable health improvement through reducing central obesity and hence cardiovascular and diabetic risk, ${ }^{18}$ yet it may translate into perhaps only $2 \%$ weight reduction for someone with morbid obesity, and is insufficient for many obese dieters to leave the obese range $\left(\mathrm{BMI} \geq 30 \mathrm{~kg} / \mathrm{m}^{2}\right)$.

These benefits are further threatened by an average annual weight increase of $0.5-1 \mathrm{~kg}$. Thus 3-5 kg loss will barely combat expected weight increase over 5-10 years, will have minimal impact on the current obesity burden and, contrary to the high hopes of every dieter, will rarely achieve anywhere near an ideal weight.

The health benefits from small or modest weight reduction are likely to be obscured if crude obesity register statistics are used to indicate performance, because significant change will be almost impossible to demonstrate. Even where concerted action produces weight reduction, existing methods can feasibly treat only 50-100 patients per practice per year, ${ }^{17}$ which is well short of a population effect, as this would cater for hardly $1 \%$ of an average practice population of $6000,{ }^{19} 23 \%$ of whom are likely to have obesity.

\section{ADVANTAGES OF MAINTAINING SMALL WEIGHT LOSS AND BENEFITS OF EXERCISE}

Health professionals could usefully deliver specific guidance about realistic long-term goals, the benefits of exercise independently of any weight reduction, and the worthwhile merits of any weight loss to help people avoid the trap of perceiving small weight loss as failure, particularly when it results in worthwhile improvements in health. Because a sense of failure is very damaging to motivation and self-esteem, both of which are required for any degree of weight control, addressing unrealistic goals may reduce any sense of failure regarding modest weight loss.

A Cochrane review of the effects of exercise on overweight and obesity showed that taking part in exercise (without dieting) had small effects on weight loss but clear cardiovascular benefits. ${ }^{20}$ Increased weight loss was found when exercise and dieting were combined, but cardiovascular benefits were demonstrable even without any weight change. Poirier and Després reported that even where weight loss is minimal, individuals with obesity and a good level of cardiorespiratory fitness are at reduced risk for cardiovascular mortality compared to lean but unfit individuals. ${ }^{21}$ Similar findings were seen in a large Swedish study which showed that the raised cardiovascular risk associated with high body fat percentage is reduced by physical activity. ${ }^{8}$

Thus, when recommending weight maintenance or weight constancy, patients should separate exercise goals from any expectation of weight loss to reduce unrealistic expectations and promote 
better continuance with exercise programmes that give clear cardiovascular benefits, despite a limited effect on weight.

\section{EVIDENCE TO SUPPORT PROMOTION OF WEIGHT CONSTANCY}

In situations where previous weight-loss attempts have consistently failed, promotion of weight constancy without attempting further weight loss is worthwhile. This may help to avoid rebound weight gain after dieting and exposure to an emotional cycle of success/failure.

A search for evidence to support this hypothesis was performed using the Cochrane database and a PubMed review of the US National Library of Medicine. Very few studies were found that assessed weight maintenance, and no specific reference was found regarding the concept of weight constancy. Levine and colleagues assessed two programmes which aimed to prevent further weight gain in normal or overweight women, and a control group. There were mixed results: the majority of women who had weight concerns focused on weight loss and were not interested in the idea of preventing further weight gain, yet the study confirmed that dieting was a predictor of further weight gain. Only $40 \%$ of their sample maintained their baseline weight over 3 years, and these women were the least likely to have tried dieting. ${ }^{22}$

Metabolic models have been described that suggest weight constancy is more likely to be achieved than maintenance of significant weight reduction. Obesity becomes a permanent condition once it develops, in part because of irreversible changes in 'metabolic sensing' neurons that regulate energy intake, expenditure, and storage, resulting in a permanent upward resetting of body weight set-point when genetically predisposed individuals become obese. ${ }^{23,24}$

While evidence for programmes promoting weight maintenance or weight constancy are still lacking, there is a clear call for more research in this area. ${ }^{21,25,26}$ Nafziger and colleagues call for broad educational efforts to promote weight constancy, particularly in adults usually considered to be at low risk for weight gain. Their study showed that younger people of normal body weight and without health conditions were the least likely to maintain a constant body weight over a 10 -year period. ${ }^{27}$

\section{WEIGHT CONSTANCY REQUIRES EFFORT AND IS NOT AUTOMATIC}

In contrast to current weight-loss strategies, reigning in over-ambitious weight-loss targets and promoting weight constancy could be achievable in primary care. It would require educational resources for staff and patients to convey the established benefits of separating the advantages of exercise from weight-loss goals, and to minimise problems associated with attempting unrealistic weight loss.

From a motivational viewpoint it is easier to achieve weight constancy than to lose weight. The approach is clinically worthwhile and is potentially practical in primary care, although we acknowledge that evidence is, as yet, inconsistent. Currently, such an approach is being directed at childhood obesity as highlighted in public service agreement targets set by the Department of Health, Department for Education and Skills, and Department of Culture Media and Sport. Their targets have recently changed from 'halting the year-on-year rise in obesity among children under the age of 11 years by 2010', to 'reducing the proportion of overweight and obese children to 2000 levels by 2020 '. ${ }^{28}$ However, no similar target exists for adults.

In light of a systematic review showing that $70 \%$ of obese adolescents grow into obese adults, preventing child obesity would reduce the number of obese adults in the future. ${ }^{29}$ A corresponding strategy to halt further adult weight increase would reduce progression from overweight to obesity to morbid obesity, with consequent reductions in weight-related illness which are otherwise projected to increase according to both 2010 and 2020 estimations in line with current obesity trends. A drop of one BMI unit, requiring roughly 2-3\% weight loss for someone with a high BMI, would reduce the incidence of type 2 diabetes by $13 \%$, which would be of great benefit in population terms. ${ }^{18}$ Equally, adopting weight constancy and thus avoiding the predicted $3 \mathrm{~kg}$ increase over 4 years would generate the same risk reduction. Thus, in light of ongoing obesity trends and limited evidence of the effectiveness of interventions, there is a strong argument for developing and evaluating prevention measures that aim to maintain existing weight, thereby preventing expected increases.

\section{WEIGHT CONSTANCY CAN BE PROMOTED WITH PRACTICAL AND SIMPLE STEPS}

Until there is evidence for more successful weightreduction strategies, primary care could move towards protecting any weight loss and promoting weight constancy. The National Weight Control Registry in the US follows up over 4000 people who have maintained significant weight loss. ${ }^{30}$ Participants are eligible for entry to the registry if they maintain a minimum of $13.6 \mathrm{~kg}$ reduction for at least a year, but the register's actual average is $33 \mathrm{~kg}$ for an average of 5 years. Evaluation reveals that certain 


\section{Table 1. Key steps in long-term weight-loss maintenance.}

Steps for weight maintenance

\begin{tabular}{|c|c|}
\hline ter weight & Additional health benefits \\
\hline $\begin{array}{l}\text { Regular exercise (around } 1 \text { hour } \\
\text { daily to maintain significant weight } \\
\text { loss; weight constancy would require less) }\end{array}$ & $\begin{array}{l}\text { Improves all aspects of health, such as } \\
\text { reduced stroke, diabetic, and osteoporosis } \\
\text { risks, and improved self-esteem }\end{array}$ \\
\hline Regular breakfast consumption & $\begin{array}{l}\text { Reduces hunger and tendency to } \\
\text { snack; improves nutritional balance of } \\
\text { diet, for example, folate and fibre intake }\end{array}$ \\
\hline Eating low-calorie, low-fat foods & $\begin{array}{l}\text { Generally linked to higher fresh produce } \\
\text { intake and hence better nutritional balance } \\
\text { and fibre intake }\end{array}$ \\
\hline Regular weighing, most days & $\begin{array}{l}\text { Reduces sense of denial about overweight } \\
\text { and obesity; reduces fear of weighing }\end{array}$ \\
\hline $\begin{array}{l}\text { Consistent eating patterns on } \\
\text { weekdays and weekends }\end{array}$ & $\begin{array}{l}\text { Promotes better satiety and reduces } \\
\text { hunger and chaotic eating patterns that } \\
\text { may be linked to high-calorie intake and } \\
\text { episodes of loss of control over eating, } \\
\text { or binge-eating episodes }\end{array}$ \\
\hline
\end{tabular}

simple steps predict long-term weight-loss maintenance, as listed in Table 1. These approaches have also been confirmed in 2004 HealthStyles survey in the US, which adds support to the present hypothesis that these steps will help weight constancy even where weight loss is not attempted. ${ }^{31}$

While the concept of regular weighing of children has not been widely evaluated, and is not a specific recommendation, encouraging adults to be regularly aware of their weight improves the chances of weight stability. It is far less daunting to tackle yesterday's extra pound than to face larger amounts of weight gain revealed by occasional weight measurements.

In view of the clear health benefits of maintaining a healthy weight, advocating weight loss is reasonable where there is a good chance of success or where no weight-control measures have previously been tried. There is a need to promote the message that $5 \%$ weight reduction can lead to up to $30 \%$ reduction in central adiposity, which brings about significant improvements in health, even if patients remain in the obese range..$^{32}$ However, when previous dieting attempts have consistently failed, the alternative approach of weight constancy should be explored. Further evaluation of this approach may broaden the evidence base for primary care weight management as a whole. Availability of more resources outlining weight-stability goals may encourage greater participation of primary care workers in weight management. Holistically, health can improve even if weight does not change. Most importantly, when patients have achieved any weight loss, care should be invested in helping them to maintain it.

\section{KEY POINTS}

- Primary care staff should discourage overambitious weight-loss targets because evidence shows poor long-term outcomes.

- Without action, average weight is increasing by $0.8 \mathrm{~kg}$ per year in the UK.

- Practical resources are required regarding the benefits of weight constancy, the importance of weight maintenance after weight loss, and the merits of exercise independent of weight change.

- There is a need to publicise the message that a $5 \%$ weight reduction can give $30 \%$ reduction in central adiposity, with significant health improvements even if still obese.

- Effort is needed to help patients to maintain any weight loss: in today's obesity-promoting environment, weight constancy could be equated with success, and weight maintenance considered a bonus.

\section{Compteting interests}

The authors have stated that there are none

\section{Discuss this article}

Contribute and read comments about this article on the Discussion Forum: http://www.rcgp.org.uk/bjgp-discuss

\section{REFERENCES}

1. Lean M, Gruer L, Alberti G, Sattar N. ABC of obesity. Obesity can we turn the tide? BMJ 2006; 333(7581): 1261-1264.

2. Department of Health. Health survey for England 2002. London: The Stationery Office, 2004

3. Jain A. Treating obesity in individuals and populations. $B M J$ 2005; 331(7529): 1387-1390.

4. Department of Health. Forecasting obesity to 2010. http://www.dh.gov.uk/en/Publicationsandstatistics/Publications/ PublicationsStatistics/DH_4138630 (accessed 29 Nov 2007).

5. Winett RA, Tate DF, Anderson ES, et al. Long-term weight gain prevention: a theoretically based internet approach. Prev Med 2005; 41(2): 629-641.

6. Mann T, Tomiyama AJ, Westling E, et al. Medicare's search for effective obesity treatments: diets are not the answer. Am Psychol 2007; 62(3): 220-233.

7. Yusuf S, Hawken S, Ounpuu S, et al. Effect of potentially modifiable risk factors associated with myocardial infarction in 52 countries (the INTERHEART study): case-control study. Lancet 2004; 364(9438): 937-952.

8. Calling S, Hedblad B, Engström G, et al. Effects of body fatness and physical activity on cardiovascular risk: risk prediction using the bioelectrical impedance method. Scand J Public Health 2006; 34(6): 568-575.

9. House of Commons Health Committee. Obesity: third report of session 2003-2004, Volume 1. London: The Stationery Office, 2004.

10. Brønnum-Hansen H, Juel K, Davidsen M, Sørensen J. Impact of selected risk factors on quality-adjusted life expectancy in Denmark. Scand J Public Health 2007; 35(5): 510-515.

11. Avenell A, Broom J, Brown TJ, et al. Systematic review of the long-term effects and economic consequences of treatments for obesity and implications for health improvement. Health Technol Assess 2004; 8(21): iii-iv, 1-182.

12. Clegg A, Colquitt J, Sidhu M, et al. Clinical and cost effectiveness of surgery for morbid obesity: a systematic review and economic evaluation. Int J Obes Relat Metab Disord 2003; 27(10): 11167-11177.

13. National Institute for Health and Clinical Excellence. Obesity guidance on the prevention, identification, assessment and management of overweight and obesity in adults and children. 
Clinical Guideline 43. London: NICE; 2006

http://www.nice.org.uk/CG043 (accessed 29 Nov 2007).

14. Padwal RS, Majumdar SR. Drug treatments for obesity: orlistat, sibutramine and rimonabant. Lancet 2007; 369(9555): 71-77.

15. National Obesity Forum. Long-term maintenance. http://nationalobesityforum.org.uk/content/blogcategory/29/171/ (accessed 29 Nov 2007).

16. Lavin JH, Avery A, Whitehead SM, et al. Feasibility and benefit of implementing a slimming on referral service in primary care using a commercial weight management partner. Public Health 2006; 120(9): 872-881.

17. McQuigg M, Brown J, Broom J, et al. Empowering primary care to tackle the obesity epidemic: the Counterweight Programme. Eur J Clin Nutr 2005; 59(Suppl 1): S93-100.

18. Lee M, Aronne LJ. Weight management for type 2 diabetes mellitus: global cardiovascular risk reduction. Am J Cardiol 2007; 99(4A): 68B-79B.

19. Royal College of General Practitioners. General practice in the UK: a basic overview. Information sheet 4. London: Royal College of General Practitioners, 2005

20. Shaw K, Gennat H, O’Rourke P, Del Mar C. Exercise for overweight or obesity. Cochrane Database Syst Rev 2006; 4: CD003817.

21. Poirier P, Després JP. Exercise in weight management of obesity. Cardiol Clin 2001; 19(3): 459-470.

22. Levine MD, Klem ML, Kalarchian MA, et al. Weight gain prevention among women. Obesity 2007; 15(5): 1267-1277.

23. Levin BE. Factors promoting and ameliorating the development of obesity. Physiol Behav 2005; 86(5): 633-639.

24. Levin BE. Why some of us get fat and what we can do about it. J Physiol 2007; 583(Pt 2): 425-430.

25. Catenacci VA, Wyatt HR. The role of physical activity in producing and maintaining weight loss. Nat Clin Pract Endocrinol Metab 2007; 3(7): 518-529.

26. Flynn MA, McNeil DA, Maloff, B, et al. Reducing obesity and related chronic disease risk in children and youth: a synthesis of evidence with 'best practice' recommendations. Obes Rev 2006; 7(Suppl 1): 7-66.

27. Nafziger AN, Lindvall $\mathrm{K}$, Norberg M, et al. Who is maintaining weight in a middle-aged population in Sweden? A longitudinal analysis over 10 years. BMC Public Health 2007; 7: 108.

28. Department of Health. Government response to report on tackling childhood obesity. London: Department of Health, 2006.

http://www.dh.gov.uk/en/Publicationsandstatistics/Pressreleases/ DH_4130965 (accessed 29 Nov 2007).

29. Parsons TJ, Power C, Logan S, Summerball CD. Childhood prediction of adult obesity: a systematic review. Int J Obes 1999; 23: $\mathrm{S} 1-\mathrm{S} 107$

30. Hill JO, Wyatt H, Phelan S, Wing R. The National Weight Contro Registry: is it useful in helping deal with our obesity epidemic? J Nutr Educ Behav 2005; 37(4): 206-210.

31. Kruger J, Blanck HM, Gillespied C. Dietary and physical activity behaviours among adults successful at weight loss maintenance. Int J Behav Nutr Phys Act 2006; 3: 17.

32. Phelan S, Wadden TA, Berkowitz RI, et al. Impact of weight loss on the metabolic syndrome. Int J Obes 2007; 31(9): 1442-1448. 